\title{
Root Mean Square
}

National Cancer Institute

\section{Source}

National Cancer Institute. Root Mean Square. NCI Thesaurus. Code C73485.

A statistical measure of the magnitude of a set of variable values. The root mean square is the square root of the mean value for the squares of the original values. 